\title{
Pain as the Perception of Someone: An Analysis of the Interface Between Pain Medicine and Philosophy
}

\section{Emmanuel Bäckryd ${ }^{1}$ iD}

Published online: 23 June 2018

(c) The Author(s) 2018

\begin{abstract}
Based largely on the so-called problem of "asymmetry in concept application", philosopher Murat Aydede has argued for a non-perceptual view of pain. Aydede is of course not denying basic neurobiological facts about neurons, action potentials, and the like, but he nonetheless makes a strong philosophical case for pain not being the perception of something extramental. In the present paper, after having stated some of the presuppositions I hold as a physician and pain researcher, and after having shortly described Aydede's critique of perceptual theories of pain, I make a constructive proposal centred around the concept of pain as the perception of some-one, not some-thing. In doing so, I propose that there often is a problematic duality at work when we think about pain, namely the mental/extramental duality. This prereflective mindset creates difficulties when reflecting over pain. Instead, I propose the body/world duality as being more helpful. Two neologisms, cosmoception and egoception, are presented as an alternative to the twin concepts of exteroception and interoception. It is argued that the new concepts have the advantage of not pushing our thought into a mental/extra-mental dichotomy. Hence, when in pain (which is an instance of egoception), I get epistemic access to the body that is I, to how I fare in this world. From that perspective, pain is not the perception of something, but of someone-namely, the self. In the final part of the paper, this proposal is discussed in dialogue with a paper from phenomenological thinker Jennifer Bullington.
\end{abstract}

Keywords Cosmoception · Egoception · Exteroception · Interoception · Pain · Perception

Emmanuel Bäckryd

emmanuel.backryd@regionostergotland.se

1 Pain and Rehabilitation Center, Department of Medical and Health Sciences, Linköping University, 58185 Linköping, Sweden 


\section{Background}

In a paper published in The Journal of Philosophy in 2009, Murat Aydede asked whether feeling pain really is the perception of something [2]. In the present paper, I will use Aydede as one of two dialogue partners, and I will propose that the difficulties that Aydede finds in reasoning about pain reveal a pre-reflective and problematic duality in the way we often think about pain. In putting forward this proposal, I will try to combine insights from pain medicine and neurobiology (fields in which I am professionally trained) with philosophical reasoning (a field in which I have no formal training). The present paper will unfold in four parts. First, I will state some of the presuppositions I hold as a physician and pain researcher. These presuppositions form an essential background for the rest of the paper. Second, I will shortly describe Aydede's critique of perceptual theories of pain. Third, based on my presuppositions and in dialogue with Aydede, I will move on to making a constructive proposal centred on the concept of pain as the perception of some-one, not something. Fourth, using Bullington [9] as my second dialogue partner, I will evaluate my proposal as well as Aydede's from a phenomenological point of view.

\section{The Pain Medicine Perspective}

\section{The Definition of Pain}

Being a physician and pain researcher, I am heavily influenced by some key concepts widely shared by the scientific and medical communities, and these concepts will now be briefly reviewed in order to hopefully create common ground between the present writer and a philosophically trained would-be reader.

The most commonly used definition of pain among pain scientists and health care personnel emphasizes the subjectivity of the pain experience. According to the definition formulated by the international association for the study of pain (IASP), pain is "an unpleasant sensory and emotional experience associated with actual or potential tissue damage, or described in terms of such damage" [14]. The definition emphasizes the subjectivity of pain (it is an "experience"), and it also states that it has both a sensory aspect and an emotional aspect. Further, the connection to actual tissue damage is not obligatory, as it is enough that the experience is "described in terms of such damage". The definition also has a note that is worth quoting at full length:

The inability to communicate verbally does not negate the possibility that an individual is experiencing pain and is in need of appropriate pain-relieving treatment. Pain is always subjective. Each individual learns the application of the word through experiences related to injury in early life. Biologists recognize that those stimuli which cause pain are liable to damage tissue. Accordingly, pain is that experience we associate with actual or potential tissue damage. It is unquestionably a sensation in a part or parts of the body, but it is also 
always unpleasant and therefore also an emotional experience. Experiences which resemble pain but are not unpleasant, e.g., pricking, should not be called pain. Unpleasant abnormal experiences (dysesthesias) may also be pain but are not necessarily so because, subjectively, they may not have the usual sensory qualities of pain. Many people report pain in the absence of tissue damage or any likely pathophysiological cause; usually this happens for psychological reasons. There is usually no way to distinguish their experience from that due to tissue damage if we take the subjective report. If they regard their experience as pain, and if they report it in the same ways as pain caused by tissue damage, it should be accepted as pain. This definition avoids tying pain to the stimulus. Activity induced in the nociceptor and nociceptive pathways by a noxious stimulus is not pain, which is always a psychological state, even though we may well appreciate that pain most often has a proximate physical cause.

The IASP definition is firmly anchored in both clinical practice and pain research, and even though it might be in need of an update [23], it is unlikely that it will be dramatically changed anytime in the near future. The definition mirrors a deeply seated conviction that pain, as being a "psychological state", must always be respected as such. Such is the power of this definition that some authors have questioned the notion that one could even conceivably search for pain biomarkers [15]. According to this view, there is a logical contradiction (and an ethical danger) in the attempts to find objective biomarkers for subjective states like pain.

\section{Nociception and Pain}

Let us now look more closely at the last sentence of the note to the IASP definition, which states that "activity induced in the nociceptor and nociceptive pathways by a noxious stimulus is not pain". Here, the concepts of nociception and nociceptive pathways are contrasted to pain. According to IASP, nociception is "the neural process of encoding noxious stimuli", and a noxious stimulus is "a stimulus that is damaging or threatens damage to normal tissues" [14]. Simply put, "encoding" here means that physical information is "transformed" into "electrical impulses" that quickly travel in a nerve towards the brain. Hence, nociception is something rather objective, and activity in the nociceptive pathways is (at least theoretically) measurable electrophysiologically [16].

The contrast between nociception and pain is important for pain researchers and pain physicians, and this distinction seems rather unique compared to other fields of medicine. For instance, there is to my knowledge no widespread term to denote activity in the optic nerve. I do not think ophthalmologists usually contrast vision with what we could perhaps could call "opticoception" (i.e., electrical activity in the optic nerve) in the way pain physicians differentiate between nociception and pain. I think this is for a good reason. There is something special about pain (and other bodily sensations) that has prompted the development of concepts that are not needed in ordinary perception. This will be discussed more below. 


\section{The Biopsychosocial Model}

The biopsychosocial model has had a great impact on pain medicine [12]. In a widely influential paper published in Science in 1977, psychiatrist George L. Engel introduced the biopsychosocial model of health and disease [5, 11]. Engel argued that the prevailing biomedical model, based on reductive physicalism and mindbody dualism, had come to a dead end. Engel was not denying the overwhelming advances of modern medicine, but he thought there was a need for a more holistic reframing of medical science. He wrote that the doctor "must weigh the relative contributions of social and psychological as well as of biological factors implicated in the patient's dysphoria and dysfunction as well as in his decision to accept or not accept patienthood and with it the responsibility to cooperate in his own health care" [11].

The biopsychosocial model fits well with the multifaceted view of pain implicit in the IASP definition. For instance, it is widely recognized that affective factors like fear [22] and depression [17] are important to assess in pain patients, although the causal relationships are complex and difficult to disentangle [17, 24]. The biopsychosocial model is consistent with the view of the brain as an active system that filters, selects and, through descending neural pathways, modulates nociceptive input from the periphery [18-21].

\section{Chronic Pain as a Disease in Its Own Right}

Finally, it is important to contrast acute pain and chronic pain. Generally speaking, chronic pain, i.e. lasting for more than 3-6 months, is not meaningful in the sense that acute pain is. Chronic pain is often pain that has become a disease in its own right. In short: chronic pain can be thought of as a disease of the nociceptive system; the nociceptive system has become "over-reactive". It has been suggested that the propensity of humans for chronic pain is a by-product of the high survival value of acute pain. According to this view, because the organism cannot afford missing lifethreatening damage, the nervous system is biased in favour of pain sensitivity [8].

I do not think that chronic pain conditions should be the foundation of a philosophical analysis of pain. After all, if one wants to think about what vision is, does one start by analysing different disturbances in the vision field? Probably not. If I want to reflect on vision, I will probably not start by reflecting on glaucoma, cataract, or retinitis pigmentosa. Most probably, I will instead start by considering "normal" cases of vision, e.g., how should one philosophically analyse what happens when one sees an orange? Of course, a philosophical understanding of the meaning of vision must be integrated and congruent with an understanding of the pathologies of vision, but it seems to me that the fundamental understanding of vision is not predicated on how vision can be disturbed in different diseases. However, when philosophers reason about pain, they often start from cases of chronic pain. For instance, Aydede uses examples from phantom pain and referred pain [1]. This seems somewhat problematic to me. I think the first step when reflecting philosophically about 
pain is to analyse acute pain; introducing chronic pain at the outset risks confusing the picture too much. Once a solid philosophical understanding of acute pain has been gained, one could (and should) go on reasoning about the phenomenon of chronic pain (which can be thought of as acute pain gone awry).

\section{The Non-perceptual View of Pain}

According to Aydede, while pain scientists over the past decades have been moving from a perceptual ${ }^{1}$ view of pain towards a view emphasizing the subjectivity of the pain experience, many philosophers have been moving in the other direction [3]. Setting aside for a moment the fact that Aydede here seems to ignore the whole phenomenological tradition (are they not too philosophers?), there is thus a substantial number of philosophers who argue for a perceptual view of pain. And why shouldn't they? Consider vision and pain. Both experiences are profoundly connected to electrical activity in nerve pathways. If vision is considered perceptual (which no one denies), why shouldn't pain? Indeed, to many non-philosophers, the idea of pain being something "non-perceptual" may seem preposterous. Why would anyone believe pain to be non-perceptual? Are the proponents of this view denying basic biological facts about neurons, action potentials, nociceptive pathways, and the like? And still, paradoxically, pain researchers (who are very much aware of the relevant neurobiology) often defend a non-perceptual view of pain, emphasizing its subjectivity and differentiating it from nociception (see the IASP definition above). What is going on here?

\section{Some Basic Distinctions}

First, let us clarify some basic concepts. Once again, Aydede shall be our guide. It is here important to distinguish between the concepts of introspection, interoception, and exteroception, and between two uses of the term perception. The distinctions are depicted in Fig. 1, which is based on [4]. In short, perception in the broad sense can be divided into (1) introspection (first-person access to one's own mental states) and (2) perception in the narrow sense (epistemic access to something extra-mental). The latter can itself be divided into interoception (2a) and exteroception (2b). When Aydede talks about perception, he means the narrow sense, and I shall do the same. Perception, in the narrow sense, is epistemic access to something extra-mental; Aydede often uses the example of a red apple that one can see. As a contrast, introspection (not to be confused with interoception) is first-person access to one's own mental state. Metaphorically speaking, in introspection I gaze deep down inside myself, whereas perception is outward-looking. At least, this is true for the kind of perception called exteroception. In interoception, I get epistemic access to something extra-mental which, however, is also something "inner", a state of my body. If

\footnotetext{
1 "Perceptual" here means the perception of an object "out there", i.e., to use Aydede's wording, epistemic access to something extra-mental (see below).
} 


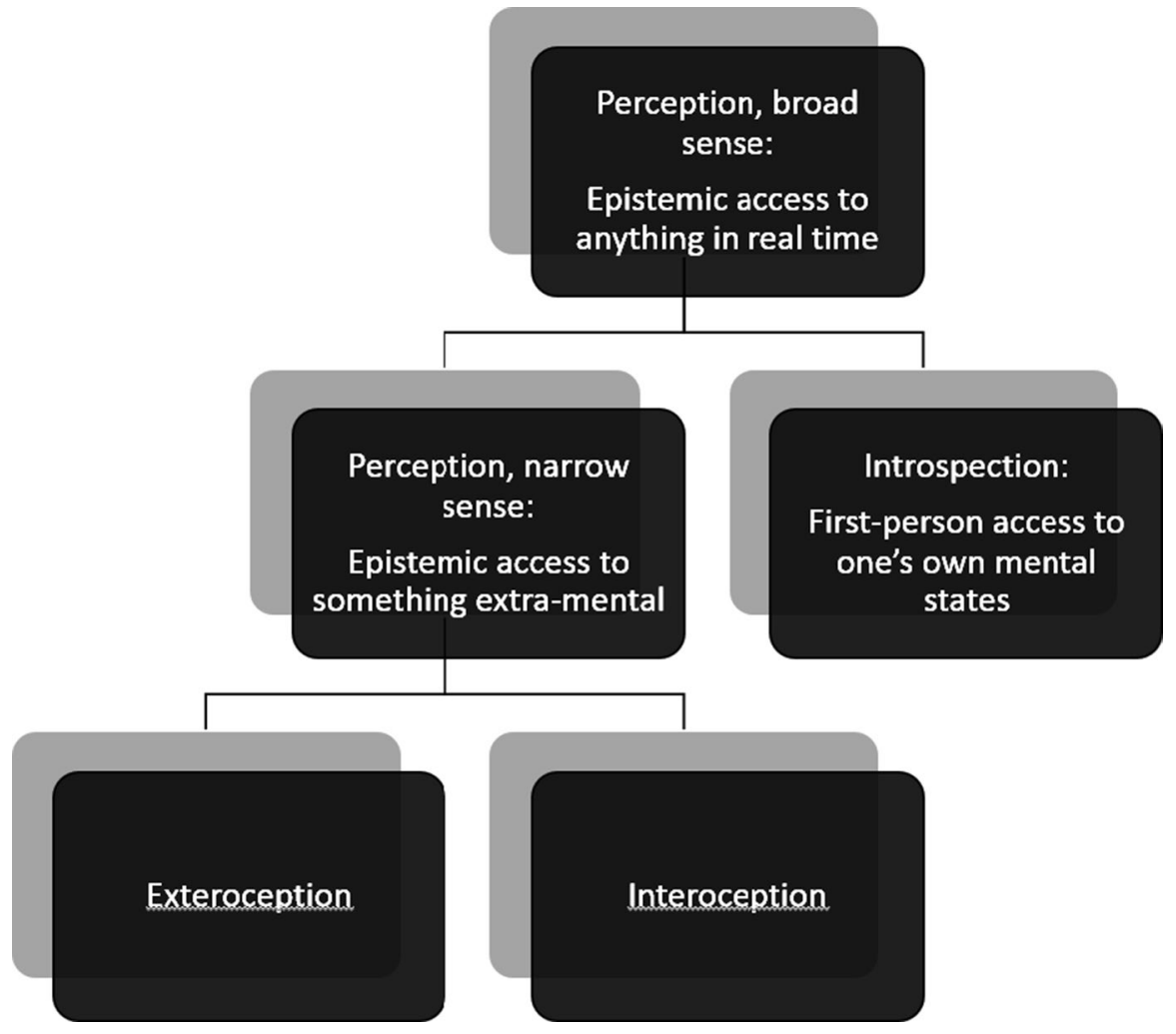

Fig. 1 Basic distinctions of terms related to perception, based on Aydede [4]

I have a chest pain, this is interoception-I get epistemic access to something that is "located" outside of my mind, but this is a particular form of perception, a perception which is about the state of my body, not something in the "outer world". As we shall see below, I contend that there is a problematic duality at work here, but for the time being, the definitions and distinctions summarized in Fig. 1 will serve us well.

\section{Murat Aydede and the Non-perceptual View of Pain}

Murat Aydede is a very articulate proponent of a non-perceptual view of pain. In his 2009 paper, Aydede came to the conclusion that feeling pain is not perceiving something extramental [2]. According to him, pain is not an instance of ordinary perception, i.e., it is not "perception of one's immediate extramental environment including one's body" [3]. Pain is not seen as an instance of perception (in the narrow sense). Rather, pain is an example of introspection (see Fig. 1). In Aydede's own words: "I think that PRT [perceptual/representational theory of pain] should be rejected: pain experiences are not perceptual" [4]. 
Of course, Aydede is not denying that the experience of pain is related to neural sensory mechanisms. In his own words, and using the above-mentioned term nociception:

Given the overwhelming neuroscientific evidence, it is foolish to deny that nociception is a genuine sensory modality. But this was not our question. Our question is rather whether the experiences this sensory modality helps to generate are genuinely perceptual. Perception requires some cognitive uptake or recognitional response to incoming sensory information: a merely sensory experience does not become perceptual until some sort of categorization can occur. [2].

Why does Aydede find a perceptual view of pain unconvincing? According to him, the main difficulty for a perceptual view of pain is what he calls the "asymmetry in concept application" for pain compared to e.g. vision [3]. When seeing something, we are not interested primarily in our own experience but in the thing that we actually see "out there"; the experience of seeing is (so to speak) transparent to the concept application-i.e., I can without problem apply the concept of the red apple that I see to the apple itself. Not so with pain. When experiencing pain, the experience itself takes centre-stage. Indeed, the very concept of pain is not applied to what causes the pain, but to the experience itself. A thorough discussion of Aydede's views falls outside the scope of this paper (indeed, the present writer would not be able to do justice to his arguments); the interested reader is referred to Aydede's own writings. Suffice it to say that, based on the "asymmetry in concept application", Aydede makes a strong philosophical case against viewing pain as a form of perception.

However, it is also important to understand that even a perceptual view of pain does not entail a rejection of the subjectivity of the pain experience; what it does is to place pain on par with other sensory experiences like vision or hearing. As Aydede explains, for the perceptual theorist,

There may be philosophical problems about how privacy, subjectivity and incorrigibility are possible in a completely physical world, but if there are such problems, they are general problems about having perceptual experience of any kind, not necessarily pertaining to pains and other intransitive bodily sensations [3] (emphases added).

Hence, for the perceptual theorist, in that sense, there is nothing special about pain; pain has to do with the perception of tissue damage. What is special with pain, the perceptual theorist acknowledges, is that the application of the concept is odd: it is applied not to tissue damage itself, but to the subjective experience. Compared to e.g. vision, there is what Aydede calls an "asymmetry in concept application" for pain [3]. Nonetheless, according to perceptual theorists, the flow of information being the same in pain and vision, both are instances of perception. However, as we have seen, Aydede does not agree.

I concur with Aydede that there is something peculiar with pain and other bodily sensations-a peculiarity that might justify the rejection of pain as the 
perception of something. However, I think that the peculiarity of pain, and the problems many theorists (including Aydede) encounter when reflecting upon pain, might (at least in part) be due to an entrenched and deeply problematic dualism between the mental and the extra-mental. I propose that exposing this problematic duality, and replacing it by another (in my opinion) more defensible duality, would clarify the issues at stake. Given this more defensible duality, pain could be viewed not as the perception of something, but of someone-namely, the self.

\section{Pain as the Perception of Some-One}

\section{A Pervasive Dichotomy}

I contend that Aydede's writings unveil a problematic dichotomy between the categories of the mental and of the extra-mental. This dichotomy seems rather selfevident to him, and it permeates the papers I have read. The mental versus extramental dichotomy seems to be grounded in the preponderance given to the brain as over the body as a whole. Hence, what takes place in the body (presumably with the exception of the brain) is "extra-mental", and it is from that point of view that the concept of interoception is understood. Remember that, according to the distinctions depicted in Fig. 1, interoception is a form of perception-perception being defined as epistemic access to something extra-mental. Hence, the dichotomy between mental and extra-mental is the lens through which the distinctions of Fig. 1 are understood. When for instance Aydede writes about "one's body parts" [2, p. 538], the dichotomy is at work; an alternative wording would have been "in parts of the body". Another example is when he writes about the view according to which"perception is essentially an activity of gathering information about one's immediate external environment, that is, environment external to one's mind and experiences, where this environment involves one's body or events internal to one's body" [1, p. 15]. Here, Aydede seems to be saying that one's body is part of the "external environment"!

\section{Cosmoception and Egoception}

This mental versus extra-mental dichotomy seems unsatisfactory. Instead of arguing against it at length, I will here propose an alternative, replacing the twin concepts of exteroception and interoception by what I will call cosmoception and egoception. The basic dichotomy is hence no longer the mental/extra-mental but the distinction between world and body. The difference may seem small, but it seems to me that it is profound.

Cosmoception (from cosmos, "world" in Greek) is, broadly speaking, equivalent to exteroception. In cosmoception, I gain epistemic access to something "outside of me". When I see a red apple on the table, I get epistemic access to precisely that objective fact (George Berkeley notwithstanding). Egoception (from ego, "I" in Greek), on the other hand, corresponds broadly to interoception. Egoception 
includes the skin and other visible parts of the body, hence also parts of the body that are not "on the inside". Indeed, the term interoception seems to imply that it has to do with what happens on the inside, "under the skin". But my skin is also me. And when my skin is damaged, I get epistemic access to that through pain/egoception. Cosmoception is about the world outside my body; egoception is about my body, it is about the self, it is about me and my place in the world, about how the world affects the body that is I.

These two neologisms have the advantage of not pushing our thought into a mental/extra-mental or an inner/outer dichotomy. Of course, the contrast between cosmoception and egoception is itself a dichotomy, but it seems to me to be a much fruitful one in its anti-cartesianism. It goes without saying that I'm not denying that some phenomena can be described as mental, whereas others are extra-mental. But when the mental/extra-mental dichotomy is given preponderance over the dichotomy between body and world, problems arise when reflecting over pain (as I propose can be seen in the writings of Aydede).

\section{The Example of Pain and Touch}

Let us look at pain and touch as examples, not from the perspective of a mental/ extra-mental duality but from the perspective of a body/world duality. When I carefully touch the edge of a sharp knife with the tip of my finger, I can sense its sharpness. I get epistemic access to the fact that the knife "out there" is sharp, i.e., I get epistemic access to information about the world around me (i.e., around the body that is I). There is a sharp knife "out there" in cosmos. This is cosmoception. However, if I cut myself a second later, I will feel pain. The pain experience is then not about the world, it's about me and my place in the world. The pain experience tells me that the world has affected me in a dangerous way. By the sensation of pain, I get epistemic access to how I fare in the world; I don't get epistemic access to the world itself. This is egoception.

Of course, there are similarities between the experience of sharpness and the experience of pain, as in both cases action potentials travel in neurons from the periphery to the brain. But the experience is different, the locus of attention being the world or the self, cosmoception or egoception. The body that is me is not an object among other objects in the world, it is my perspective on the world. When I feel that a candle flame is warm, I get epistemic access to something that is happening in the world. If I approach my hand to much, I will feel pain, because I now feel that my body is dangerously affected. ${ }^{2}$

I think that the "asymmetry in concept application", which is central to Aydede's thinking here, forces him into a non-perceptual view of pain precisely because he reasons from the perspective of mental/extra-mental. When viewed from a body/

\footnotetext{
${ }^{2}$ Many thanks to an anonymous reviewer, who made me aware of the pain/touch distinction being described by Hume: "The heat of a fire, when moderate, is suppos'd to exist in the fire; but the pain, which it causes upon a near approach, is not taken to have any being, except in the perception [13, p. 139)."
} 
world perspective, however, there is arguably nothing strange about the "asymmetry in concept application". On the contrary, it is to be expected. Pain having to do with egoception, the concept will be applied not to the world "out there" but to myself. The key, it seems to me, is to leave the mental/extra-mental perspective and instead view pain from a body/world perspective.

\section{Phenomenological Perspectives}

Thinking about the body and its place in the world leads us to the field of phenomenological analysis. I will now contrast my proposal and Aydede's view with phenomenological thinking as expressed by Jennifer Bullington in her paper Embodiment and chronic pain: implications for rehabilitation practice [9].

As a physician, I am trained to consider the body from an "objective" and scientific point of view. When I meet a patient, his or her body can hence be seen as an objective "thing" in the universe, a thing that can be scientifically studied. But, as historian Johanna Bourke aptly puts it, "the body is never pure soma" [6]. I take this to mean, among other things, that our understanding of the body is always socioculturally embedded. On an even more profound level, from the perspective of the patient, the view of the body as an "objective" phenomenon is deeply problematic. Although many patients seem to have internalized an "objective" view of the body (which translates into expectations to be "fixed" by the physician), phenomenological thinking reminds us that for the patient herself/himself, the body is arguably not first and foremost a thing in the universe. For the patient, the body as object can be contrasted to the "lived body" of phenomenological thinking. In Bullington's words:

Our tendency to think of the body as something we have rather than what we are is reinforced by influences from natural science, which teach us to objectify our own bodies in lines with natural scientific descriptions of the body. The human body becomes first and foremost an objective body. Medical knowledge and practice are built upon this conceptualization of the body as a material, functioning system, consisting of muscles, bones and tissues, nerves and chemical substances. [9].

Following philosopher Merleau-Ponty, the "lived body" is my perspective on the world, not an object for study "from the outside". This is a phenomenological way of thinking, the focus of phenomenology being "the way in which the world appears (shows itself) to human beings in and through subjectivity (consciousness)" [10]. Phenomenological thinkers study the subjective experience as it appears "within". To cite Bullington again:

The lived body is this unity of mind-body-world. It is the structure of the whole, a whole that we have learned to conceptually split up into separate compartments. The lived body is the human beings' lived relationship to the meaningful human world. These three poles, mind, body and world, are actually intertwined and cannot be properly understood apart from one another. It is our way of thinking that divides them, not our experience [9]. 
Here, it is worth noting that Bullington speaks about three "poles" (mind, body, world), and the unity of these poles ("mind-body-world"). The whole point of the lived body discourse seems to be to provide "a non-dualistic way of understanding mind and body as well as articulating a philosophically sound holistic conception of man in the world" [9]. However, when talking about "man in the world", as well as in Bullington's article at large, one can sense that the triad mind-bodyworld really boils down to a dichotomy, Bullington herself using the expressions "mind-body pole" and (repeatedly) "world pole". So perhaps, instead of talking of the mind-body-world unity, it would be more correct to speak about the (mind-body)-world unity, mind and body being "united" at a more fundamental level. Indeed, my position, as expressed in part 3 of the present paper, could be seen as such a (mind-body)-world view. In contrast, Aydede's thinking on this matter could perhaps be summarized by mind-(body-world $)$, i.e., Aydede focuses on a mental/extramental duality, whereas my distinction between cosmoception and egoception is grounded in a fundamental duality between me as a person (mind-body) and the world.

Like Bullington, I hold to "a non-dualistic way of understanding mind and body" [9], but I think it helpful to acknowledge that this non-dualistic view of man presupposes a kind of more fundamental duality between person and world. Indeed, the "point" of consciousness seems to be to establish a sort of boundary between self and world. At the very least, pain seems to have that function, as effectively expressed by leprosy specialist Paul Brand when discussing the deleterious effects of not being able to feel pain:

Pain [provides] a sort of boundary of self. Loss of sensation destroys that boundary, and now my leprosy patients no longer felt their hands and feet as a part of self. Even after surgery, they tended to view their repaired hands and feet as tools or artificial appendages. They lacked the basic instinct of selfprotection that pain normally provides. One of the boys said to me, «My hands and feet don't feel part of me. They are like tools I can use. But they aren't really me. I can see them, but in my mind they are dead.» I heard similar comments often, underscoring the crucial role pain plays in unifying the human body. [7].

Let us return to the concepts of cosmoception and egoception. In cosmoception, the "lived body", i.e., my body as it is appears to me, not to any external observer, remains in the shadows, allowing me to relate to the world in an "open" way. The world is centre stage, and I can attend to it without disruption. There is indeed a (mind-body)-world unity. In pain egoception however, the mind-body takes a step forward and comes centre stage. I can't ignore it any longer, or rather, I can't ignore myself. Pain is the perception of some-one, of some-body, of one body, my body, the body that is me. The world gets less important, it shrinks, and in severe cases the horizon collapses back on the self, the horizon rushes onto me, it encircles me, and I live in a small world. The "lived body", when in pain, gets centre stage and distorts my experience of the world. In extreme cases (e.g. in torture), the person in pain experiences only the self; nothing "exists" except pain. Hence, pain egoception tells me not something about the world itself, but something about my place in the world, 
about the existentially worrying fact that I can potentially be engulfed by the world, i.e. that my existence is threatened by the world. As egoception, pain has an intrinsic existential flavour, telling me something important about my place in this world and the vulnerability inherent in my being in it.

\section{Conclusion}

When we are in pain, we seem neuroanatomically "hard-wired" to focus our attention on our own body. For Aydede, this "asymmetry in concept application" is an argument for viewing pain as something non-perceptual. It seems to me, however, that the philosophical problem Aydede describes is predicated on a problematic mental/extra-mental dichotomy. I have here proposed that it seems more fruitful to view the phenomenon of pain from a body/world perspective, and I have accordingly introduced the concepts of cosmoception and egoception. Neologisms set aside, the central point I want to make is that pain can indeed be viewed as perceptual provided we leave the menta/extra-mental paradigm behind. We do perceive something in pain-we perceive ourselves, and how we "fit" in the world. Aydede is right insofar that pain is not the perception of something in the world "out there". But pain seems to be more than just introspection (see Fig. 1), i.e. pain is more than only "firstperson access to one's own mental states". Pain is the perception of someone. It is not merely an introspective mental phenomenon, it is epistemic access to how the surrounding world (which is indeed a dangerous place) affects the body that is me.

Acknowledgements Many thanks to Professor Kristin Zeiler, Linköping University, who commented on an early version of this paper. Needless to say, all shortcomings of the present paper remain the sole responsibility of the author.

\section{Compliance with Ethical Standards}

Conflict of Interest The author declares that there is no conflict of interest.

Open Access This article is distributed under the terms of the Creative Commons Attribution 4.0 International License (http://creativecommons.org/licenses/by/4.0/), which permits unrestricted use, distribution, and reproduction in any medium, provided you give appropriate credit to the original author(s) and the source, provide a link to the Creative Commons license, and indicate if changes were made.

\section{REFERENCES}

1. Aydede, M. (2005). Introduction: A critical and quasi-historical essay on theories of pain. In M. Aydede (Ed.), Pain-New essays on its nature and the methodology of its study (pp. 1-58). Cambridge, MA: MIT Press.

2. Aydede, M. (2009). Is feeling pain the perception of something? The Journal of Philosophy, $106(10), 531-567$.

3. Aydede, M. (2013). Pain. The Stanford encyclopedia of philosophy. http://plato.stanford.edu/archi ves/spr2013/entries/pain/. Accessed November 1, 2015. 
4. Aydede, M. (2016). Pain: Perception or introspection?. http://faculty.arts.ubc.ca/maydede/Ayded e_PainIntrospection.pdf. Accessed November 14, 2016.

5. Borrell-Carrio, F., Suchman, A. L., \& Epstein, R. M. (2004). The biopsychosocial model 25 years later: Principles, practice, and scientific inquiry. The Annals of Family Medicine, 2(6), 576-582.

6. Bourke, J. (2014). The story of pain: From prayer to painkillers. Oxford: Oxford University Press.

7. Brand, P. W., \& Yancey, P. (1997). The gift of pain. Grand Rapids, MI: Zondervan.

8. Brodal, P. (2010). Pain. In P. Brodal (Ed.), The central nervous system: Structure and function (pp. 204-214). Oxford: Oxford University Press.

9. Bullington, J. (2009). Embodiment and chronic pain: implications for rehabilitation practice. Health Care Analysis, 17(2), 100-109.

10. Bullington, J. (2013). Chapter 2: The Lived Body. In The expression of the psychosomatic body from a phenomenological perspective (pp. 19-38). Dordrecht: Springer.

11. Engel, G. L. (1977). The need for a new medical model: A challenge for biomedicine. Science, 196(4286), 129-136.

12. Gatchel, R. J., Peng, Y. B., Peters, M. L., Fuchs, P. N., \& Turk, D. C. (2007). The biopsychosocial approach to chronic pain: Scientific advances and future directions. Psychological Bulletin, 133(4), 581.

13. Hume, D. (1998). Treatise of human nature: being an attempt to introduce the experimental method of reasoning into moral subjects. Kitchener: Batoche Books. Retrieved from https://ebookcentr al.proquest.com .

14. International association for the study of pain taxonomy-pain. http://www.iasp-pain.org/Taxonomy. Accessed November 5, 2015.

15. Kalso, E. (2004). Biomarkers for pain. Pain, 107(3), 199-201.

16. Kleggetveit, I. P., Namer, B., Schmidt, R., et al. (2012). High spontaneous activity of C-nociceptors in painful polyneuropathy. Pain, 153(10), 2040-2047.

17. Linton, S. J., \& Bergbom, S. (2011). Understanding the link between depression and pain. Scandinavian Journal of Pain, 2(2), 47-54.

18. Melzack, R. (1999). From the gate to the neuromatrix. Pain, 6, S121-126.

19. Melzack, R., \& Wall, P. D. (1965). Pain mechanisms: A new theory. Science, 150(699), 971-979.

20. Ossipov, M. H., Dussor, G. O., \& Porreca, F. (2010). Central modulation of pain. The Journal of Clinical Investigation, 120(11), 3779-3787.

21. Staud, R. (2012). Abnormal endogenous pain modulation is a shared characteristic of many chronic pain conditions. Expert Review of Neurotherapeutics, 12(5), 577-585.

22. Vlaeyen, J. W., \& Linton, S. J. (2012). Fear-avoidance model of chronic musculoskeletal pain: 12 years on. Pain, 153(6), 1144-1147.

23. Williams, A. C., \& Craig, K. D. (2016). Updating the definition of pain. Pain, 157(11), 2420-2423.

24. Wise, T. N., Fishbain, D. A., \& Holder-Perkins, V. (2007). Painful physical symptoms in depression: A clinical challenge. Pain Medicine, 8(Suppl 2), S75-82. 